\title{
Pernikahan Sirri (Kontekstualisasi Pemahaman Hadis dalam Studi Kasus di Indonesia)
}

\author{
Agusri Fauzan \\ Program Studi Ilmu Hadis, UIN Fatmawati Sukarno Bengkulu \\ e-mail: agusrifauzan@gmail.com
}

\begin{abstract}
ABSTRAK. Tulisan ini bertujuan untuk membahas persfektif hadis tentang permasalahan pernikahan sirri, melalui pemahaman kontekstual dengan menggunakan pendekatan fikih, agar dapat menentukan hukum yang pasti dari berbagai variasi pernikahan sirri yang terjadi di masyarakat. Metode yang digunakan dalam tulisan ini menggunakan metode kepustakaan (library research) yaitu meneliti dan menelaah berdasarkan sumber-sumber kepustaakan. Penelitian ini bersifat deskriftif (menguraikan sumber-sumber yang diperoleh dan kemudian dianalisis) dengn menggunakan langkah kerja pemahaman hadis yang terdiri dari takhrij hadis, natijah, dan pemahaman matan. Hasil penelitian menyimpulkan bahwapernikahan sirri yang dimaksud dalam penelitian ini adalah pernikahan yang tidak sesuai sunnah, dalil-dalil yang medukung kesimpulan ini penulis dapat dari pemahaman hadis-hadis Nabi: 1. pernikahan adalah kegiatan yang tidak boleh hanya dihadiri subjek utama (mempelai pria dan wanita saja), namun harus dihadiri minimal oleh satu orang wali dan dua orang saksi, 2. Pernikahan adalah kegiatan yang tidak boleh ditutupi dan harus disebarluaskan kepada masayarakat, 3. Walimah pernikahan adalah kegiatan yang sangat diperintahkan oleh Nabi walaupun dilaksanakan secara sederhana. Walimah dapat juga berfungsi sebagai media penyebarluasan berita pernikahan
\end{abstract}

Kata kunci: Sirri, hadis, kontekstual.

\section{PENDAHULUAN}

Pernikahan sirri yang dimaksud dalam tulisan ini adalah pernikahan yang dirahasiakan dari lingkungan sosial dan tidak tercatat di KUA (Kantor Urusan Agama). Konsep pernikahan sirri yang ingin penulis ajukan sebagai permasalahan sedikit memiliki perbedaan dengan konsep pernikahan sirri menurut MUI (Majelis Ulama Indonesia) ataupun yang berkembang di masyarakat. Dalam fatwa MUI nomor 10 tahun 2008, pernikahan seperti ini disebut dengan pernikahan di bawah tangan (pernikahan di bawah tangan adalah pernikahan yang tidak dicatatkan di KUA). Pengertian seperti itulah yang berkembang dalam pemahaman masyarakat bahwa pernikahan sirri dimaknai sebagai pernikahan yang tidak dicatatakan di kantor Urusan Agama, sehingga status pernikahan tersebut tidak diakui oleh negara, dan memiliki dampak dalam pembuatan administrasi kependudukan atau administrasi kenegaraan. Dahulu, yang dimaksud dengan nikah sirri yaitu nikah yang sesuai dengan rukun-rukun nikah dan syaratnya menurut syariat Islam. Kemudian saksi atau wali diminta untuk tidak memberitahukan terjadinya pernikahan tersebut kepada khalayak ramai (masyarakat), dan dengan sendirinya tidak ada walimah 
al-ursy. ${ }^{1}$ Namun dalam tulisan ini pengertian pernikahan sirri yang ingin diangkat adalah pernikahan yang tidak tercatat di KUA serta dirahasiakan dari masyarakat umum.

Tulisan ini bertujuan untuk membahas perspektif hadis tentang permasalahan pernikahan sirri, melalui pemahaman kontekstual dengan menggunakan pendekatan fikih, agar dapat menentukan hukum yang pasti dari berbagai variasi pernikahan sirri yang terjadi di masyarakat di Indonesia. Hasil kajian dalam tulisan ini hanya berlaku dalam studi kasus di wilayah hukum negara Indonesia dan berada di wilayah komunitas masyarakat ideal. Kasus pernikahan sirri yang sejenis yang terjadi di luar wilayah Indonesia atau komunitas masyarakat Indonesia yang belum terakses Kantor Urusan Agama tidak menjadi bagian dari tulisan ini. Pada dasarnya, tulisan tentang pernikahan sirri sudah ramai sekali dibahas dalam berbgaia literatur dan tulisan, bahkan permasalahan nikah sirri ini sendiri juga sudah terdapat fatwa dari MUI. Namun, pengertian dan hukum yang muncul tentang pernikahan sirri tidak pernah tegas dan pembahsannya tidak melalui pemhanan dalil yang komprehensif.

\section{METODOLOGI}

Metode yang digunakan dalam tulisan ini menggunakan metode kepustakaan (iibrary research) yaitu meneliti dan menelaah berdasarkan sumber-sumber kepustaakan. Penelitian ini bersifat deskriftif (menguraikan sumber-sumber yang diperoleh dan kemudian dianalisis) dengn menggunakan langkah kerja pemahaman hadis yang terdiri dari takhrij al-hadits, natijah, dan pemahaman matan. Dari metode-metode ini diharapkan akan mencapai kesimpulan yang komprehensif dan dalil hukum yang kuat tentang bagaimana status pernikahan sirri yang sebenarnya melalui persfektif hadis. $^{2}$

Dalam melaksanakan takhrij al-hadits penulis langsung mengutip hadis secara utuh dari kitab hadis atau sumber primer. Dalam pengambilan kesimpulan status ke-bujjah-an hadis atau natijah, penulis juga mengutip dari pendapat dari para ulama. Sedangkan untuk pemahamannya, penulis mengutip dari berbagai literatur yang sudah memberikan penjelasan dari hadis yang dimaksud.

\section{PEMBAHASAN}

\section{Hadis-Hadis Tentang Pelaksanaan Nikah}

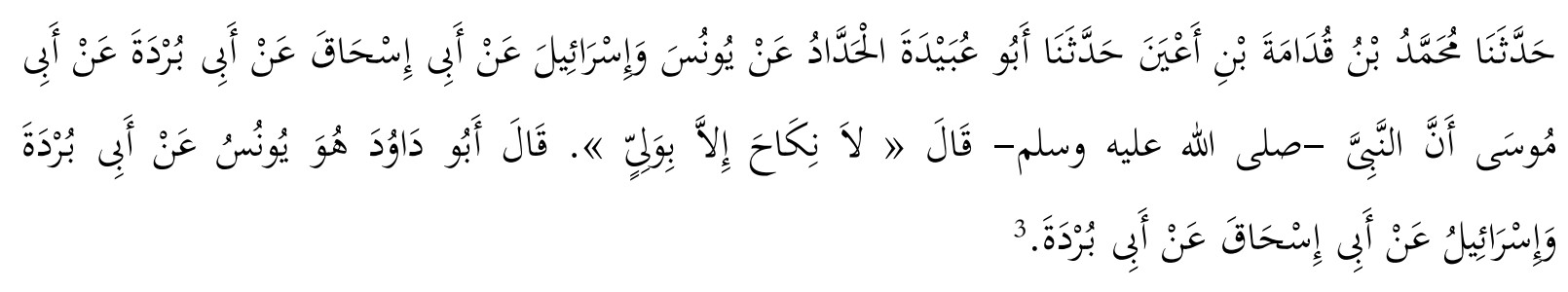

1 Sanders, Richard. "Kedudukan Istri, Anak, Dan Warisan Dalam Pernikahan Siri Yang Marak Terjadi Di Masyarakat Ditinjau Dari UU Perkawinan." Al Qodiri: Jurnal Pendidikan, Sosial dan Keagamaan 18.1 (2020): 265-275.

${ }^{2}$ M. Syuhudi Ismail. Metodologi Penelitian Hadis Nabi. (Jakarta: Bulan Bintang, 1992).

${ }^{3}$ Sulaiman bin al-Asy'ats Abu Dawud al-Sijistaniy al-Azdiy, Sunan Abi Dawud, (Beirut: Dar al-Fikr, t.th), j. 1, h. 635 
Telah menceritakan kepada kami Muhammad bin Qudamah bin A'yan, telah menceritakan kepda kami Abu Ubaidah al-Haddad, dari Yunus dan Israil dari Abi Ishaq dari Abi Burdabn dari Abi Musa babwa Nabi Shollallahu 'alaibi wa Salam telah bersabda: Tidak sah pernikahan kecuali dengan adanya wali.

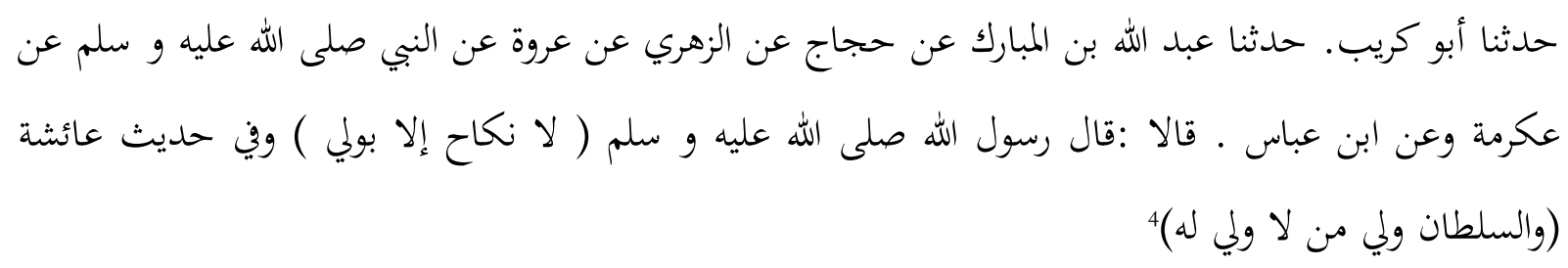

Telah menceritakan kepada kami Abu Kuraib, telah menceritakan kepada kami Abdullab Ibnul Mubarak, dari Hajjaj, dari al-Zubri, dari Umwah, dari Nabi shallallabu 'alaibi wasallam. (dalam jalur lain) dari Ikrimah dari Ibnu Abbas, keduanya berkata, "Rasulullah shallallabu 'alaibi wasallam bersabda: "Tidak ada nikah tanpa adanya wali." Dalam hadis 'Aisyah disebutkan; "Penguasa adalah wali bagi orang yang tidak mempunyai wali."

Hadis pertama menyebutkan bahwa pernikahan yang sah harus dihadiri wali dari pihak perempuan. Hadis kedua menyebutkan hal yang sama namun dengan tambahan bahwa wanita yang tidak memiliki wali maka hak walinya dapat diwakilkan kepada sultan atau pemerintahan yang sah. Dalam beberapa atsar dan jalur riwayat mursal menyebutkan bahwa pernikahan yang sah harus dihadiri wali dari pihak perempuan ditambah dua orang saksi.

Dalam tulisan ini, konteks yang akan dibahas bukanlah tentang siapa yang disebut atau berhak menjadi wali dan juga bukan membahas tentang siapa dan apa kualifikasi dari saksi. Hadishadis di atas penulis ajukan sebagai jawaban bahwa pernikahan adalah kegiatan yang tidak boleh hanya dihadiri subjek utama (mempelai pria dan wanita saja), namun harus ada orang lain yang menyaksikan pernikahan tersebut. Pernikahan yang didalam akadnya tidak ada wali (atau dihadiri wali yang tidak sah) dan tidak ada saksi (atau saksi yang tidak memenuhi kualifikasi) maka penulis menyimpulkan bahwa pernikahan seperti ini adalah pernikahan yang tidak sah.

Perkawinan adalah merupakan salah satu bentuk perjanjian yang dibuat oleh manusia, walaupun begitu akad nikah bukanlah suatu perjanjian kebendaan bukan pula dimaksudkan untuk kebendaan. Wali dan saksi mempunyai arti penting yaitu sebagai pembuktian apabila ada pihak ketiga yang meragukan perkawinan tersebut. Wali dan saksi dapat mencegah pengingkaran oleh salah satu pihak.

Wali menurut ulama empat mazhab dan Kompilasi Hukum Islam (KHI) adalah sesuatu yang sangat urgen dalam sebuah pernikahan. Ulama empat mazhab dan KHI mengatakan wajib adanya wali dalam sebuah proses pernikahan meskipun ulama Hanafiyyah berkata wali diperuntukkan hanya untuk perempuan yang belum dewasa. Akan tetapi pendapat ini mengandung kelemahan yaitu mereka terlihat mencari-cari hal yang lain yang sebenarnya sudah terdapat hukum yang sangat jelas jika dilihat dari teks hadis tersebut. Ulama empat mazhab, KHI, dan juga UU Perkawinan No. 1 Tahun 1974 sepakat bahwa wali sebagai salah satu rukun dalam pernikahan.

Saksi menurut Jumhur ulama adalah sebuah rukun pernikahan, akan tetapi sebagian ulama mazhab Maliki tidak memasukkan saksi sebagai rukun. Namun, pendapat ini juga lemah dan

\footnotetext{
${ }^{4}$ Muhammad bin Yazid Abu Abdillah al-Qazwiniy, Sunan Ibnu Majah, (Beirut: Dar al-Fikr, t.th), j. 1, h. 605
} 
menyalahi teks hadis. Permasalahan saksi dalam KHI sudah diatur secara gamblang, yang sesuai dengan pendapat Jumhur ulama. Adapun permasalahan ini jika dilihat dalam UU Perkawinan No. 1 Tahun 1974 juga tidak ada masalah, karena dalam Pasal 2 menyebutkan: pernikahan yang sah harus sesuai dengan agama yang dianut. Oleh karena itu dapat diambil kesimpulan bahwasanya semua ulama mazhab empat, KHI, dan juga UU Perkawinan No. 1 Tahun 1974 sepakat bahwa saksi sebagai salah satu rukun dalam pernikahan. ${ }^{5}$ Dalil tentang wajibnya saksi dapat diketahui dari teks hadis berikut yang diriwayatkan oleh al-Daruquthni dalam kitab sunannya:

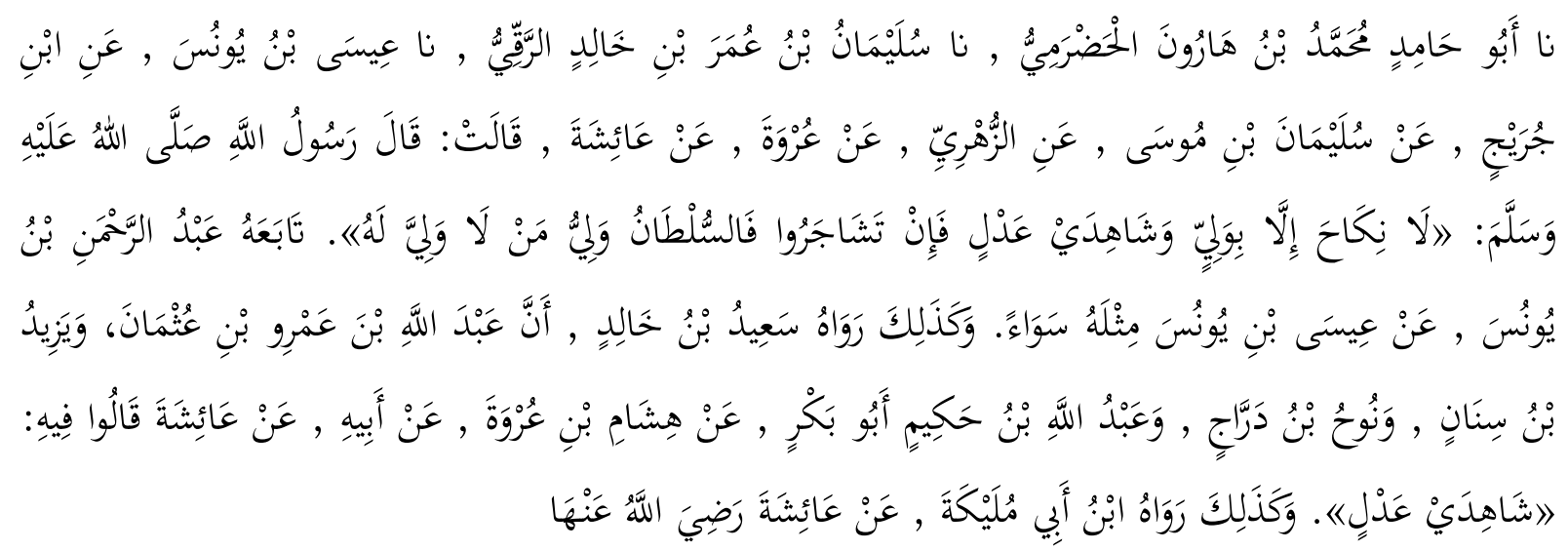

Abu Hamid Mubammad bin Harun Al Hadhrami menceritakan kepada kami, Sulaiman bin Umar bin Khalid Ar-Raqqi menceritakan kepada kami, Isa bin Yunus menceritakan kepada kami, dari Ibnu Juraij, dari Sulaiman bin Musa, dari A₹-Zubri, dari Umwah, dari Aisyah, dia berkata: Rasulullah SAW bersabda, "Nikah tidak sah kecuali jika menyertakan wali dan dua orang saksi yang adil. Jika mereka berselisih maka penguasa adalah wali bagi yang tidak mempunyai wali" Hadis ini diperkuat dengan riwayat Abdurrahman bin Yunus dari Isa bin Yunus dengan redaksi yang sama seperti tadi. Demikian pula riwayat Sa'id bin Khalid bahwa Abdullah bin Amr bin Utsman, Yazid bin Sinan, Nub bin Darraj dan Abdullab bin Hakim Abu Bakar, dari Hisyam bin Urwah, dari ayahnya, dari Aisyah. Semuanya meriwayatkan lafazh "dua orang saksi yang adil". Demikian pula riwayat Ibnu Abu Mulaikah dari Aisyah $\mathrm{R} A{ }^{6}$

\section{Hadis-Hadis Tentang Kewajiban Mengumumkan Pernikahan}

$$
\begin{aligned}
& \text { حدثنا عبد الله حدثني أبي ثنا هارون بن معروف قال عبد الله وسمعته أنا من هارون قال حدثنا عبد الله بن وهب } \\
& \text { قال حدثني عبد الله بن الأسود القرشي عن عامر بن عبد الله بن الزبير عن أبيه ان النبي صلى الله عليه و سلم قال } \\
& { }^{7} \text { : أعلنوا النكاح : }
\end{aligned}
$$

Telah menceritakan kepada kami Abdullah Telab berkata kepadaku Ayabku Telah berkata kepada kami Harun bin Ma'ruf, Abdullah telab berkata aku telah mendengarnya dari Harun, ia berkata telah menceritakan kepada kami Abdullah bin Wabb, ia berkata telah menceritakan kepadaku Abdullah bin al-

\footnotetext{
${ }^{5}$ Rinwanto, Rinwanto, and Yudi Arianto. "Kedudukan Wali Dan Saksi Dalam Perkawinan Perspektif Ulama Empat Mazhab (Maliki, Hanafi, Shafi'i Dan Hanbali)." AL MAQASHIDI 3.1 (2020): 82-96.

${ }^{6}$ Abu al-Hasan 'Ali bin Umar bin Ahmad bin Mahdi bin Mas'ud bin al-Nu'man bin Dinar al-Baghdadiy, Sunan al-Daruquthni, (Mesir: Wazarah al-Aufaq al-Mishriyyah, t.th), j. 8, h. 346.

${ }^{7}$ Ahmad bin Hanbal, Musad Ahmad bin Hanbal, (Kairo: Muassasah Qurtubah, t.th), j. 4, h. 5.
} 
Aswad al-Qursiy, dari Amir Ibnu Abdullab Ibnu al-Zubair, dari ayahnya Radliyallaabu 'anbu babwa Rasulullah Shallallaabu 'alaibi wa Sallam bersabda: "Sebarkanlah berita pernikahan."

$$
\begin{aligned}
& \text { أخبرنا الحسن بن سفيان الشيباني قال : حدثنا حرملة بن يهيى قال : حدثنا ابن وهب قال : حدثني عبد الله بن } \\
& \text { الأسود عن عامر بن عبد الله بن الزبير عن أبيه أن رسول الله صلى الله عليه و سلم قال : ( أعلنوا النكاح ) قال } \\
& \text { الشيخ رضي الله عنه : معناه : أعلنوا بشاهدين عدلين } \\
& \text { قال شعيب الأرنؤوط : إسناده حسن } 8
\end{aligned}
$$

Telah mengabarkan kepada kami al-Hasan bin Sufyan al-Syaibaniy, ia berkata: telab menceritakan kepada kami Harmalah bin Yabya, ia berkata: telah menceritakan kepada kami Ibnu Wabb, ia berkata: telah menceritakan kepadaku Abdullah bin al-Aswad dari Amir Ibnu Abdullah Ibnu al-Zubair, dari ayahnya Radliyallaabu 'anbu bahwa Rasulullah Shallallaabu 'alaibi wa Sallam bersabda: "Sebarkanlah berita pernikahan."

Hadis di atas adalah hadis abad yang diriwayatkan oleh Ahmad bin Hanbal dan Ibnu Hibban melalui Abdullah bin Zubair dari Zubair bin Awwam. Syu'aib al-Arnauth memberikan penilaian bahwa sanad hadis ini hasan. Hadis yang berstatus hasan dapat diamalkan dan dapat dijadikan bujjah. ${ }^{9}$ Hadis ini memberikan informasi kepada kita, bahwa Nabi Muhammad memerintahkan umatnya untuk mengumumkan pernikahan. Hikmah dari diumumkannya akad nikah adalah agar pasangan terbebas dari tuduhan zina atau fitnah yang keji. Serta selain itu, dapat mendapatkan keberkahan serta doa dari masyarakat.

Hadis tersebut di atas dipahami secara berbeda oleh para ulama tentang apa yang dimaksud dengan 'mengumumkan pernikahan'. Imam Syafi'i dan Abu Hanifah menyatakan bahwa jika telah ada dua (2) orang laki-laki yang 'adil sebagai saksi (Abu Hanifah menambahkan boleh jika hanya satu orang laki-laki dan dua orang perempuan) maka pernikahan tersebut tidak lagi dikategorikan sebagai pernikahan sirri (rahasia atau tersembunyi). Mereka menganggap bahwa persaksian mereka itu sebagai bentuk i'lan atau pengumuman pernikahan. Sedangkan ulama dari kalangan Malikiyah berpendapat bahwa nikah sirri itu adalah adanya pesan termasuk kepada para saksi untuk menyembunyikan pernikahan, oleh sebab itu menurutnya pengumuman tersebut adalah wajib hukumnya, dan tidak cukup hanya dengan adanya saksi. Lebih lanjut ulama Malikiyah menyatakan bahwa pernikahan yang disembunyikan adalah batil (tidak sah). Pendapat Imam Malik ini dipertegas lagi dalam al-Muwatta' bahwa nikah sirri merupakan perkawinan yang terlarang. Dengan kata lain pendapat ulama Malikiyah ini menentang pendapat Syafi'i dan Abu Hanifah yang menganggap bahwa keberadaan saksi merupakan wujud dari al-i'lan (pengumuman), sehingga jika saksi telah hadir maka pengumuman tidak perlu. Perbedaan tafsiran hadis dari para ulama tersebut di atas seharusnya menjadi acuan yang kuat untuk menganalisa nikah sirri yang

\footnotetext{
8 Muhammad bin Hibban bin Ahmad Abu Hatim al-Tamimiy al-Bistiy, Shahih Ibnu Hibban, (Beirut: Muassasah al-Risalah, 1994), j. 9, h. 374

${ }^{9}$ Damanik, Nurliana. "Teori Pemahaman Hadis Hasan." Shabih (Jurnal Kewahyuan Islam) 2.2 (2020). Lihat juga: Pardosi, Fakhrurrozi. "Kajian Tentang Hadis Hasan." Waraqat: Jurnal Ilmu-Imu Keislaman 2.2 (2017): 19-19.
} 
telah merajalela di Indonesia dan pelakunya bahkan dari berbagai kalangan termasuk kelompok agamawan. ${ }^{10}$

Ibnu Hibban sebagai mukhakrrij hadis ini lebih condong kepada pendapat Abu Hanifah dan Imam Syafi'i yang berpendapat i'lan atau pengumuman pernikahan sudah cukup manakala disaksikan oleh dua orang saksi. Namun dalam hal ini, penulis lebih cenderung mendukung pendapat Malikiyah yang mewajibkan mengumumkan pernikahan kepada masyarakat umum. Pendapat Malikiyah ini cenderung lebih menyelamatkan hak perempuan dalam kasus-kasus pernikahan sirri yang ada di Indonesia. Selain itu, kesanggupan mengumumkam pernikahan kepada masyarakat juga menjadi uji publik bahwa pernikahan yang dilangsungkan tidak bermasalah (baik hukum agama, hukum negara, dan adat).

\section{Hadis-Hadis Tentang Walimah}

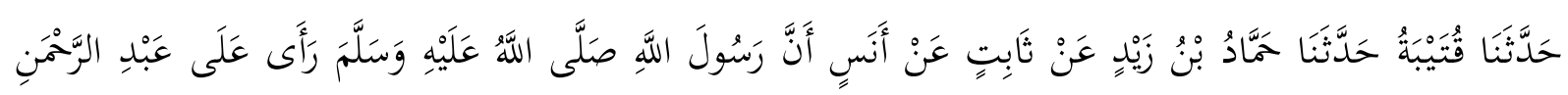

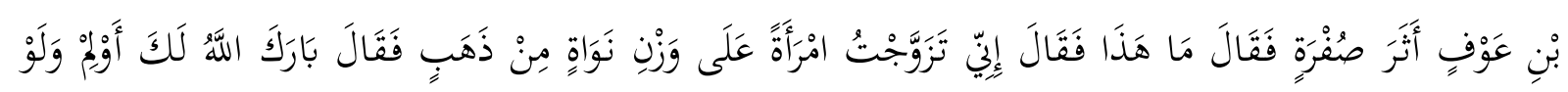

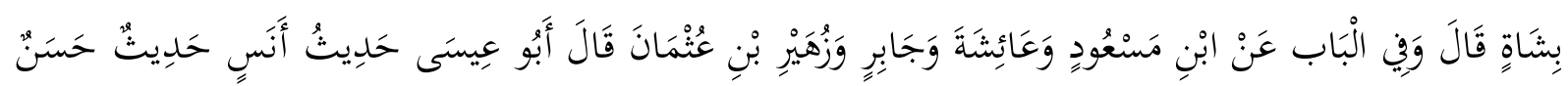

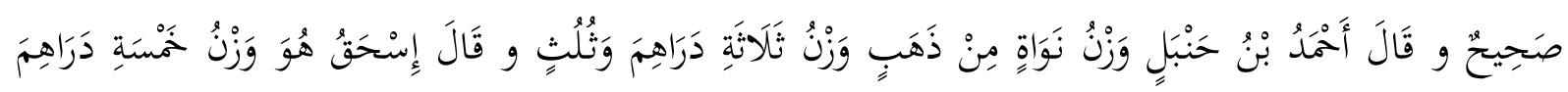

Telah menceritakan kepada kami Qutaibah, telah menceritakan kepada kami Hammad bin Zaid dari Tsabit dari Anas bahwa Rasulullah shallallabu 'alaibi wasallam melihat bekas warna kuning (bekas minyak za'faran) pada Abdurrahman bin auf. Beliau bertanya: "Apakah itu?" Dia menjawab; "Saya baru saja menikahi seorang wanita dengan mahar sekeping emas." Beliau mendo'akan: "Barakallahu Laka (semoga Allah memberkatimu), adakankah walimah walau hanya dengan (memotong) seekor kambing." (Abu Isa alTirmidzi) berkata; "Hadis semakna diriwayatkan dari Ibnu Mas'ud, Aisyah, Jabir dan Zubair bin 'Utsman." Abu Isa berkata; "Hadis Anas merupakan hadis hasan sabih. Ahmad bin Hanbal berkata; 'Wąnu Nawat' adalah ukuran tiga sepertiga dirham. Ishaq berkata; itu adalab lima sepertiga dirbam."11

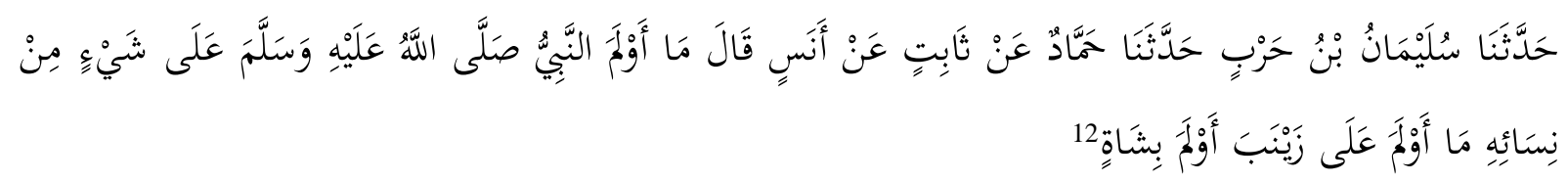

Telah menceritakan kepada kami Sulaiman bin Harb Telab menceritakan kepada kami Hammad dari Tsabit dari Anas ia berkata; Nabi shallallabu 'alaibi wasallam tidak pernah mengadakan

10 Arsyad, Aisyah. "Menuju Fikih Gender: Analisis Hadis Tentang Perintah Mengumumkan Pernikahan." Tabdis: Jurnal Kajian Ilmu Al-Hadis 8.2 (2019).

11 Hadis yang semakna dengan ini juga diriwayatkan oleh al-Bukhari, Muslim, Abu Dawud, Ibnu Majah, alDarimi, Imam Malik, dan Imam Ahmad bin Hanbal. Lihat: Maudina, Aldila. Walimah Urs dalam Perspektif Hadis. BS thesis. 2018., h. 32.

12 Muhammad bin Ismail Abu Abdillah al-Bukhari al-Ja'fi, Shahih al-Bukhari, (Beirut: Dar Ibnu Katsir, 1987), j. 5, h. 1983. 


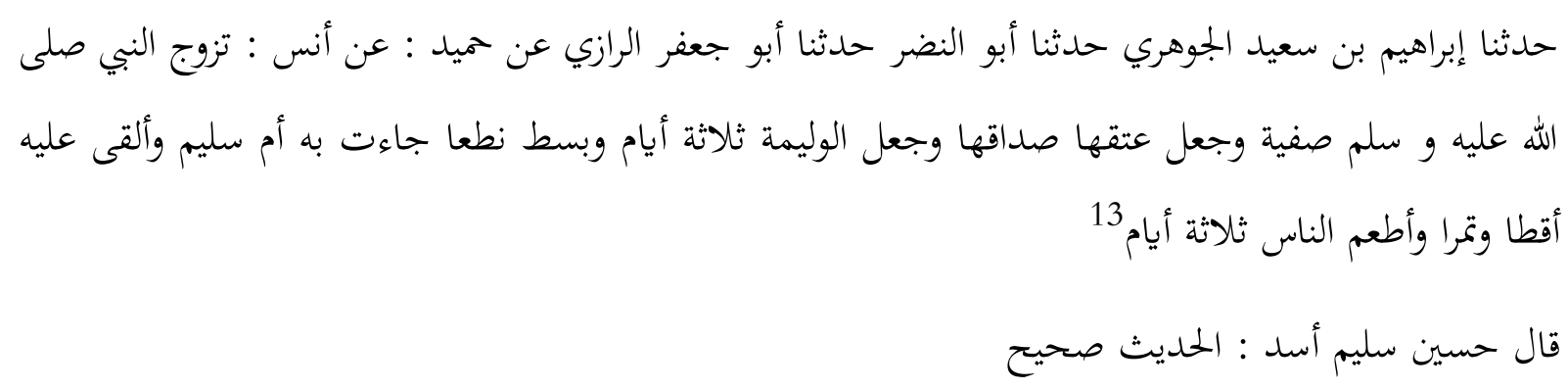

Telah menceritakan kepada kami Ibrahim bin sa'id al-Jaubari, telah menceritakan kepada kami Abu an-Nadhar, Telah menceritakan kepada kami Abu Ja;far al-Rąi dari Hamid, Dari Anas: Nabi Muhammad menikahi Shafiyyah dan menjadikan pembebasannya sebagai mahar dan membuat walimah selama tiga hari secara sederhana, datanglah Ummu Sulaim dan membentangkan kulit untuk alas dan meletakkan keju dan kurma dan menjamu orang-orang selama tiga hari.

Hadis pertama tentang walimah di atas diriwayatkan oleh al-Bukhari dan beberapa mukharrij lainnya, yaitu: Muslim, Abu Dawud, Ibnu Majah, al-Darimi, Imam Malik, dan Imam Ahmad bin Hanbal. Karena disepakati oleh al-Bukhari dan Muslim, dapat disimpulkan hadis ini bersatus shabih dan dapat dijadikan bujjah. Hadis ini berisi perintah Rasulullah kepada Abdurrahman bin 'Auf agar mengadakan walimah setelah pernikahannya walaupun hanya dengan seekor kambing. kalimat "Awlim walau bi syattin” Dalam syarah Aunul Ma'bud merupakan batas minimal seseorang dalam melaksanakan walimah al-ursy dengan memotong seekor kambing. Tetapi para ulama sepakat tidak ada batasan dalam hal ini. Sajian yang dihidangkan dalam walimah disesuaikan dengan kemampuan laki-laki dan situasi dan kondisi saat itu. ${ }^{14}$

Hadis kedua tentang walimah di atas diriwayatkan oleh al-Bukhari melalui Sahabat Anas bin Malik. Hadis ini berisi informasi bahwa Nabi Muhammad melaksanakan walimah setelah melaksanakan pernikahan dengan Zainab. Saat itu, beliau mengadakan walimah dengan seekor kambing. Hadis ini memiliki kesesuaian antara perintah Nabi kepada Abdurrahman bin 'Auf dan perbuatan yang Nabi kerjakan sendiri dalam pelaksanaan walimah pernikahan.

Hadis ketiga tentang walimah di atas diriwayatkan dalam Musnad Abi Ya’la, melalui sahabat Anas bin Malik. Menurut Husain Salim al-Asad hadis ini berstatus shahih. Hadis ini mengabarkan tentang walimah Nabi Muhammad saat menikah Shafiyyah. Nabi melaksanakan walimah secara sederhana selama tiga hari dengan memberikan jamuan keju dan kurma. Dari beberapa hadis yang telah ditemukan oleh penulis, hadis kedua dan ketiga memiliki keterkaitan. Teks hadis yang kedua menunjukan bahwa Nabi SAW mengadakan walimah untuk istri nya dengan menyembelih seekor kambing. Teks hadis yang ketiga Nabi Saw mengadakan walimah dengan kurma, dan keju tanpa adanya daging. Hal ini menunjukkan Nabi sangat menganjurkan

\footnotetext{
13 Ahmad bin 'Ali bin al-Mutsanna abu Ya'la al-Maushuli al-Tamimi, Musnad Abi Ya'la, (Damaskus: Dar alMa'mun li al-Turats, 1984), j. 6, h. 446.

${ }^{14}$ Abu Toyyib Muhammad Syamsul Haq al-Adzim, Aunul Ma'bud, (t.tp: Baitul Afkar Ad-Dauliyah, t.th), J. 6, h. 140
} 
untuk mengadakan walimah walau hanya dengan seekor kambing ataupun makanan apapun yang tersedia saat itu. Walimah disunatkan supaya pernikahan tersebut diketahui orang banyak. ${ }^{15}$

\section{KESIMPULAN}

Pernikahan sirri adalah pernikahan yang tidak sah secara hukum Islam dan secara otomatis menjadi pernikahan yang tidak diakui secara hukum Negara Indonesia. Dalam hukum Islam, pernikahan dianggap sah manakala dihadiri oleh wali dan orang saksi. Untuk menjamin kepastian hukum, Negara Indonesia mewajibkan pencatatan pernikahan di Kantor Urusan Agama.

Penikahan adalah sebuah ibadah yang harus diketahui oleh orang lain. Dalam pernikahan yang sah dan dapat diakui secara hukum Islam dan Negara, pernikahan tersebut harus dihadiri oleh minimal oleh seorang wali dan dua orang saksi. Hukum Negara Indonesia menambahkan pernikahan tersebut harus tercatat di Kantor Urusan Agama. Pernikahan yang sengaja ditutupi dari orang lain (tidak diumumkan) atau sengaja tidak dicatatkan di Kantor Urusan Agama adalah pernikahan batil menurut pemahaman mazhab maliki. Penulis mendukung pendapat Malikiyah yang mewajibkan mengumumkan pernikahan kepada masyarakat umum. Pendapat Malikiyah ini cenderung lebih menyelamatkan hak perempuan dalam kasus-kasus pernikahan sirri yang ada di Indonesia.

Pernikahan sebaiknya diumumkan kepada masyarakat umum melalui pelaksanaan walimah. Pelaksanaan walimah pernikahan sangat dianjurkan walaupun hanya menghidangkan makanan yang sederhana. Selain itu, kesanggupan (melaksanakan walimah) mengumumkam pernikahan kepada masyarakat juga menjadi uji publik bahwa pernikahan yang dilangsungkan tidak bermasalah (baik hukum agama, hukum negara, dan adat).

\section{REFERENSI}

Abu al-Hasan 'Ali bin Umar bin Ahmad bin Mahdi bin Mas'ud bin al-Nu'man bin Dinar alBaghdadiy. T.th. Sunan al-Daruquthni. Mesir: Wazarah al-Aufaq al-Mishriyyah.

Abu Toyyib Muhammad Syamsul Haq al-Adzim. t.th. Aun al-Ma'bud. t.tp: Baitul Afkar AdDauliyah.

Ahmad bin 'Ali bin al-Mutsanna Abu Ya'la al-Maushuli al-Tamimi. 1984. Musnad Abi Ya'la. Damaskus: Dar al-Ma’mun li al-Turats.

Ahmad bin Hanbal. t.th. Musnad Ahmad bin Hanbal. Kairo: Muassasah Qurtubah. Muhammad bin Hibban bin Ahmad Abu Hatim al-Tamimiy al-Bistiy. 1994.Shahih Ibnu Hibban. Beirut: Muassasah al-Risalah.

Arsyad, Aisyah. 2019. "Menuju Fikih Gender: Analisis Hadis Tentang Perintah Mengumumkan Pernikahan." Tahdis: Jurnal Kajian Ilmu Al-Hadis 8.2.

Damanik, Nurliana. 2020. "Teori Pemahaman Hadis Hasan." Shahih (Jurnal Kewahyuan Islam) 2.2.

15 Imam Nawawi, al-Majmu Syarah al-Muhadzdzab, terj: Abdul Somad dan Umar Mujtahid, (Jakarta: Pustaka Azzam, 2010), j. 6, h. 503 
Imam Nawawi. 2010. Al-Majmu Syarah Al-Muhadzdzab, terj: Abdul Somad dan Umar Mujtahid. Jakarta: Pustaka Azzam.

Ismail, M. Syuhudi, 1992. Metodologi Penelitian Hadis Nabi. Jakarta: Bulan Bintang.

Maudina, Aldila. 2018. Walimah URS Dalam Perspektif Hadis. BS thesis.

Muhammad bin Yazid Abu Abdillah al-Qazwiniy. T.th. Sunan Ibnu Majah. Beirut: Dar al-Fikr

Muhammad bin Ismail Abu Abdillah al-Bukhari al-Ja'fi. 1987. Shahih al-Bukhari, Beirut: Dar Ibnu Katsir.

Pardosi, Fakhrurrozi. 2017. "Kajian Tentang Hadis Hasan." Waraqat: Jurnal Ilmu-Ilmu Keislaman 2.2.

Rinwanto, Rinwanto, and Yudi Arianto. 2020. "Kedudukan Wali Dan Saksi Dalam Perkawinan Perspektif Ulama Empat Mazhab (Maliki, Hanafi, Shafi'I Dan Hanbali)." Al Maqashidi 3.1.

Sanders, Richard. 2020. "Kedudukan Istri, Anak, dan Warisan dalam Pernikahan Siri yang Marak Terjadi di Masyarakat Ditinjau dari UU Perkawinan." Al Qodiri: Jurnal Pendidikan,Sosial dan Keagamaan 18.1.

Sulaiman bin al-Asy'ats Abu Dawud al-Sijistaniy al-Azdiy. T.th. Sunan Abi Dawnd, Beirut: Dar alFikr. 